Ensino, Saúde e Ambiente -VV5 (1), pp.83-93, abril. 2012

\title{
CIÊNCIA COMO HISTÓRIAS DO MUNDO: DILEMAS E DICOTOMIAS NAS AULAS DE CIÊNCIAS PARA PEDAGOGIA
}

\section{SCIENCE AS STORIES OF THE WORLD: DILEMMAS AND DICHOTOMIES ON SCIENCE CLASSES FOR PEDAGOGY}

\author{
Celso Sánchez ${ }^{1}$ e Tiago Ribeiro ${ }^{2}$ \\ ${ }^{1}$ Professor do Programa de Pós Graduação em Educação da Universidade Federal do Estado do Rio de \\ Janeiro (UNIRIO). celso.sanchez@hotmail.com \\ ${ }^{2}$ Bolsista de Iniciação Científica IC-UNIRIO, integrante da Rede de Formação Docente Compartilhada \\ (FORMAD) e do Grupo de Pesquisa: Práticas Educativas e Formação de Professores (GPPF). \\ trsunirio@gmail.com
}

\section{Resumo}

A partir de experiências investigativas com uma turma da disciplina Ciências Naturais II, no curso de Pedagogia da UniRio, pretende-se discutir percursos, percalços, dilemas e dicotomias presentes na formação do educador para o ensino de ciências. Por que, apesar de toda reflexão e discussão acerca da superação da concepção do ensino de ciências como mera transmissão de conhecimentos científicos, é tão difícil para os professores em formação pensar formas outras de ensinar Ciências? Através do diálogo com narrativas discentes, intenta-se enfrentar questões propostas por Roseli \& Caluzi (2004) acerca dos desafios do ensino de ciências e suas relações com o mundo cotidiano, através da reflexão da composição rizomática do conhecimento e da própria construção do conhecimento científico. Assim, faz-se uma reflexão sobre o formação docente tendo em vista a (re)significação do ensino de ciências, enquanto possibilidade para a (trans)formação de cidadãos críticos e atuantes em um mundo em crise.

Palavras-chave: ensino de ciências; formação de professores; cotidiano escolar

\begin{abstract}
From an investigative experience with a class of the discipline Natural Sciences II, in the UniRio Pedagogy course, we intend to discuss routes and difficulties, dilemmas and dichotomies present in the teachers' formation to science teaching. Although the discussions during the classes, when the overcoming of the conception of science education as the mere transmission of scientific knowlodge is pointed as a necessity, it is very difficult for students to think about other possibilities for science teaching. Why? Through dialogue with student narratives, we intend do face questions posed by Roseli \& Caluzi (2004) about science education challenges and its relation to the everyday world, through the reflection of the knowledge rhizomatic composition. Thus, it is a reflection on teacher formation with a view to (re)signification of science education as a possibility for the (trans)formation of critical and active citizens in a world in crisis.
\end{abstract}

Keywords: science education; teachers formation; school quotidian 


\section{Percursos de (re)significação e de (des)aprendizagens: para um início de conversa}

Atualmente, é muito forte o discurso segundo o qual se faz imperioso o desenvolvimento de ações efetivas que possibilitem, no cotidiano da sala de aula, movimentos de ensino-aprendizagem por meio dos quais os estudantes possam construir conhecimentos de forma ativa e autônoma, embora esta autonomia requeira mediação e interlocução com outros, estudantes e professores/as.

Essa dinâmica de garantir ao processo educativo um caráter dialógico, polifônico e multissituado é ainda um desafio, pois aprendemos a ensinar consoante um modelo em cujas bases está a busca (equivocada) pelo controle e homogeneização de tempos e aprendizagens. Tendo inculcado, então, essa forma de perceber os movimentos de aprender e ensinar, é-nos sempre uma construção o exercício de desaprender certezas e descobrir novas possibilidades, porque, como nos ensina Von Foerster (1996), só vemos o que compreendemos - é essa a realidade: a maneira como delas nos apropriamos, cerceados pela nossa (sempre transponível) percepção.

Nesse sentido, buscamos, neste trabalho, discutir uma experiência vivida ao longo de um semestre com uma turma do curso de Pedagogia da Universidade Federal do Estado do Rio de Janeiro (UNIRIO), onde, na disciplina Ciências Naturais II, foram discutidas questões sobre o ensino de ciências para os Anos Iniciais do Ensino Fundamental, salientando a importância de uma abordagem que relacione a ciência e suas interfaces com tecnologia, sociedade e ambiente, de forma enredada, a qual vem sendo chamada de abordagem CTSA $^{1}$ (Ciência-Tecnologia-Sociedade-Ambiente) no ensino de ciências (AULER e DELIZOICOV, 2001; AIKENHEAD, 2005 entre outros), isto é, uma abordagem que, rompendo com a perspectiva de uma educação bancária (FREIRE, 1982), promova ampliação de saberes e leituras mais críticas do mundo por meio da contextualização da ciência enquanto prática cultural e, portanto, produção social.

\footnotetext{
${ }^{1}$ A abordagem CTSA é fruto dos movimentos CTS que surgem no âmago das reformas curriculares do ensino de ciências a partir da emergência do pensamento ambientalista e do surgimento de novas demandas sociais a partir dos movimentos de contracultura que influenciaram os Estados Unidos e a Europa a partir do final dos anos 60. Alimentados pela necessidade de formar uma sociedade "cientificizada" que pudesse fazer frente às demandas da guerra fria e da corrida espacial, a reforma curricular do ensino de ciências acabou por trazer à tona reflexões que pretendiam açambarcar as dinâmicas relacionais das ciências com a sociedade, as tecnologias e a questão ambiental.
} 
A partir desta abordagem problematizadora do ensino de ciências, e não obstante todas as discussões, nas quais os estudantes propuseram questões filosóficas, políticas e sociais implicadas no trabalho docente, fez-se um exercício de sublinhar a importância do rompimento com o modelo clássico de ciência, que tem justificado práticas pedagógicas centradas em monoculturas de tempo e saber (Monteiro, 2011). Buscou-se refletir acerca de possibilidades abertas por uma abordagem dialógica no que tange à garantia de uma leitura mais ampla do mundo, processo no qual algumas dicotomias, permanências e mudanças, ao longo do percurso investigativo, foram se tornando evidentes.

Como mote, foi proposto, como atividade avaliativa para o encerramento do período letivo, desde o início do período, que os estudantes elaborassem um texto crítico sobre algumas temáticas acerca do ensino de ciências abordadas na sala. Após a escrita do texto, também era proposta do trabalho a elaboração de um esboço de material didático que se desafiasse a articular ciência, tecnologia, saúde e ambiente, de forma a apresentar uma proposta que fugisse à fragmentação tão comum à maioria dos materiais didáticos a que temos acesso.

Todavia, quando os estudantes foram desafiados a pensar alternativas para trabalhar ciência na escola, propondo ideias outras ao invés dos materiais didáticos disponíveis, geralmente descontextualizados e expositivos, algumas fraturas emergiram. Mesmo com toda a discussão realizada e a reflexão crítica em relação à concepção comumente presente nos materiais didáticos, no momento da realização dos trabalhos cujo intuito era, justamente, a refutação dessa lógica, a reprodução dela foi, de modo geral, mantida, por parte dos discentes da turma de Ciências Naturais na Educação II.

Podemos dizer que era notável na dinâmica da turma, nas perguntas e colocações realizadas, uma expressiva insegurança no rompimento em relação a padrões estabelecidos, como por exemplo, o uso do livro didático. A construção de críticas contudentes a este material se mostrou como um grande desafio por parte dos alunos, os quais declararam, ainda, "dificuldade" para perceber possibilidades e oportunidades para a tessitura de suas críticas e análises. Podemos falar, dessa maneira, de uma espécie de "campo de força" ao redor do intocável livro didático de ciências, que, muitas vezes, distancia-se das realidades específicas dos/as estudantes, os quais apresentam inquietações e enfrentam muitos desafios para correlacionar conceitos e apresentá-los de maneira relacional ao contexto CTSA. O livro didático em ciências, em nossa investigação, parecia, a partir de narrativas de alunos e alunas, ainda ser visto como uma 
espécie de livro-guia, como na fala a seguir, de uma aluna da turma, ao perguntar sobre o trabalho:

- Como é que eu vou propor um material para ensinar ciências sem ver lá no livro de ciências? Como é que eu vou falar mal do livro e construir um material didático, como se fosse um livro?

O que tal questionamento tem a nos dizer? Que pistas abrem-se a partir dos dilemas expressos por essa estudante do curso de pedagogia ao pensar sobre o ensino de ciências, ou, mais que isso, sobre um processo educativo baseado em matizes outras, a saber: o diálogo, a interação, a cooperação e a significação da apropriação do conhecimento para a vida?

Talvez sua fala nos aponte quão grande é a provocação de se desafiar a praticar (ou mesmo pensar) uma prática outra, porque somos todos herdeiros de um modelo científico crente no mito da neutralidade e devedores de uma compreensão do processo de aprender e ensinar como uma relação de transmissão, portanto bancária (FREIRE, 1982), motivo pelo qual temos, no mais das vezes, praticado e (re)produzido, em nossas salas de aulas, um ensino pautado na exposição, na cópia e na memorização, o qual cerceia a possibilidade de relações mais democráticas nas quais os alunos e alunas assumam seus papéis de autores/as no processo de construção e apropriação do conhecimento.

Muitas vezes, não obstante toda problematização e crítica, o livro didático acaba servindo como um instrumento/objeto reprodutor de lógicas instituídas, de uma epistemologia hegemônica que tende a nos dominar em imagens e textos da tradição que nos é imposta sem que nos seja garantido, muitas vezes, o tempo necessário para a reflexão acerca do que nos ocorre.

Tendo isso em vista, também foi interessante notar a recorrência, nas falas dos discentes, insatisfações a respeito da carga horária para as aulas de ciências. Havia um consenso de que seria necessária ampliá-la tanto ao nível da formação destes mesmos discentes, quanto também nas horas da disciplina de ciências nas séries iniciais da educação básica (antigo ensino fundamental). Nestes debates, havia também a emergência de um discurso mais profundo que se remetia à competência do pedagogo em ensinar ciências. Muitos dos discentes consideravam-se inaptos por acharem sua formação científica insuficiente.

Nestes momentos, experienciava-se uma ótima oportunidade de compartilhamento de ideias na turma. Assumimos, então, a defesa da ideia de que o 
ensino de ciências não deve ser reduzido à transmissão de conhecimentos ou de conceitos científicos, mas essencialmente deve assumir a responsabilidade sobre a formação de um espírito científico conforme nos fala Bachelard (2003), cujas características estão presentes desde a infância, como curiosidade, criatividade, inventividade, capacidade de questionamento, imaginação, enfim, aspectos do desenvolvimento psíquico e do pensamento humano, para o qual o pedagogo, sem dúvida, pode fornecer importantes subsídios em sua consolidação e construção.

Sabendo ser a maneira como aprendemos um referencial muito forte em nossas práticas; muitas vezes, ela impinge-nos maneiras de fazer, pois (des)aprender certezas para (re)aprender possibilidades é um exercício muito difícil. Nesse sentido, acabamos por ensinar ciências como algo dado, estabelecido; postura, aliás, que fortalece a caracterização dessa disciplina como exótica, repleta de curiosidades, porém desprovida de um caráter cultural e social, enfim, um saber morto, pronto e acabado, uma ciência morta (DELIZOICOV et all., 2002) cuja lógica contribui com a cisão entre ciência e cultura, entre ciência e sociedade, como se aquela fosse uma dimensão sobre-humana, alcançável por alguns esclarecidos e gênios.

De fato, a forma tradicional de ensinar ciências, por meio de apresentação e memorização de conceitos, é ainda muito forte e, porque apreendida, acaba se perpetuando e ocupando um lugar privilegiado em nossas maneiras de fazer/saber. Nesse momento, as experiências de alunos ao longo da via pesam sobremaneira, às vezes silenciando dinâmicas de formação vividas nos cursos de formação "inicial”. Os discursos se tornam fraturados, e as dicotomias se evidenciam, porque o próprio discurso não coaduna com a prática.

Todavia, ainda esse fato não é univalente. Se por um lado aponta permanências em relação ao modelo epistemológico que embasa a concepção dos docentes em formação; por outro, desnuda mudanças em processo, em desenvolvimento, porque

desenvolvimento é, sempre, movimento e transformação. A dimensão dinâmica e mutante, no entanto, deve ser entendida em sua articulação com permanências e constâncias. [...] $\mathrm{O}$ desenvolvimento humano se faz de conquistas e de perdas, envolvendo sempre alegrias e tristezas[...] (COLINVAUX, 2009, p.55).

Dessa maneira, o processo formativo é um movimento de permanências e mudanças, contínuo, multissituado, no qual experiências vividas e praticadas também 
são formação. A partir delas, outros modos de compreender podem ser construídos, antigas verdades podem ser despidas, na tensão entre o fazer-pensar. Acontecimentos vividos na prática podem, sim, questionar nossas maneiras de saber e fazer, porque um conhecimento nunca é estático, e a realidade é galhofeira: jamais é uma, sempre é móbil, de modo que, aos invés de certezas, temos, sempre, possibilidades...

\section{2. (Im)possibilidades para o ensino de ciências: mo(vi)mentos de reflexão e aprendizagem}

Começamos salientando a importância da interação e do diálogo nas relações pedagógicas por entendê-los como dimensões importantes para o aprendizado, à medida que possibilitam autonomia de fala e pensamento aos estudantes, os quais talvez possam, por esse caminho, assumir seu lugar de sujeitos ativos na construção do conhecimento.

A partir dessa perspectiva, queremos pensar, juntamente com Fumagalli (1993), um ensino de ciências compromissado com a formação do cidadão crítico e com a leitura mais ampla do mundo, porque, para nós, aprender ciências não é apenas apreender conhecimentos e conceitos científicos, porém, mais que isso, é fazer uso desses conhecimentos para agir no e sobre o mundo.

Essa assunção implica ver de outro modo o conhecimento e a própria ciência. Quanto ao conhecimento, precisamos ter em vista tratar-se de um saber social e historicamente situado; quanto à ciência, não podemos esquecer que esta é um produto cultural, portanto produzida e produtora de homens. Então, competem as perguntas: que ciência temos ensinado na escola? Que tipo de formação temos garantido aos nossos alunos?

Tal reflexão exige discutirmos a temática do ensino de ciência sem esquecermos a necessidade sempre presente de garantirmos movimentos múltiplos e singulares de ensino-aprendizagem por meio de práticas emancipatórias, a fim de legitimarmos a palavra de nossos alunos e alunas e, assim, possibilitarmos a superação da curiosidade ingênua rumo à curiosidade epistemológica (FREIRE, 1996), qual seja: aquela sob cuja visão o mundo não é natural, tampouco estático.

Dessa forma, no processo de formação docente, é importante se fazer a discussão de que, longe de estar relacionado apenas ao laboratório, à curiosidade, aos inventos, o ensino de ciência tem um papel importante na prática social, 
consubstanciando-se em um saber indispensável para a desconstrução de algumas certezas social, cultural e historicamente construídas. Em outras palavras: o conhecimento científico possibilita a participação social efetiva, uma vez que abre espaço para a construção do senso crítico (MALAFAIA, RODRIGUES, 2008), imprescindível para o exercício da cidadania e para a ampliação da leitura de mundo.

Ensinar ciência é um dever ético do professor $^{2}$, pois, por meio desta aprendizagem, vão se abrindo ao sujeito outras possibilidades de ser-estar no mundo, menos ingênuas, inclusive. Ademais, sendo a ciência parte da cultura, seu aprendizado é (mais uma) maneira de garantir ao outro sua inserção e apropriação da e na cultura, porém não como aquele que vai "consumir" cultura, e sim como aquele que, desde sempre, é produtor de cultura.

Essa concepção coloca o próprio ensino de ciência como uma ação cujo desenvolvimento viabiliza um rompimento com a dicotomia a partir da qual comumente o senso comum vê a natureza e o homem, como se daquela este não fosse parte. Assim, um ensino de ciências em cujo bojo esteja o entendimento da necessidade de que:

a formação científica das crianças e dos jovens deve contribuir para a formação de futuros cidadãos que sejam responsáveis pelos seus atos tanto individuais como coletivos, conscientes e conhecedores dos riscos, mas ativos e solidários para conquistar o bem-estar da sociedade e críticos e exigentes diante daqueles que tomam as decisões (MALAFAIA; RODRIGUES, 2008, p.4-5).

Essa proposta, ademais, dialoga com o entendimento de ciência nos próprios Parâmetros Curriculares Nacionais, para os quais ciência é uma elaboração humana para a compreensão do mundo (BRASIL, 1997). Mas de que compreensão estamos falando? Uma ciência que garante aos alunos e alunas sua percepção enquanto parte constitutiva da natureza e por ela constituída?

Durante todo o curso da disciplina Ciências Naturais na Educação II, essa temática foi amplamente discutida e refletida pelo grupo. Nas aulas, os estudantes narravam suas experiências de alunos nos anos iniciais da educação básica (antes, anos iniciais do ensino fundamental) e sobre elas refletiam criticamente. Contudo, frente ao

\footnotetext{
2 Obviamente, atribuir ao ensino de ciências a característica de ser ético não significa negar a ética inerente às demais práticas, tampouco desvalorizar o ensino de outras disciplinas. Falamos, aqui, de uma ética talvez necessária a toda prática pedagógica, qual seja: olhar o sujeito educando como produtor de conhecimento:como um legítimo outro (MATURANA, 1998).
} 
desafio de realizar um trabalho com uma proposta de ensino de ciências diferente, não faltaram objeções, como nas falas a seguir, de quatro estudantes:

- Não dá, professor! É muito difícil!

- Na prática, a coisa fica muito mais difícil do que na proposta.

- Ih! Eu pensei que era um negócio simples, mas isso é muito complicado, é um desafio danado!

- A gente espera um caminho ditado pelo professor

Dificuldade, complicação, desafio... Palavras que nos concedem algumas pistas para pensar sobre a questão que, aqui, queremos conversar. Talvez essas narrativas nos apontem (im)possibilidades do ensino de ciências na escola, as quais englobam, inclusive, as próprias práticas escolares experienciadas quando de nossa condição de alunos do ensino fundamental (e por que não médio?), de forma geral muito fortemente arraigadas nos professores principiantes, que as acabam reproduzindo, porque sair desse lugar poderia ser, talvez, como admoestou uma estudante da disciplina Ciências Naturais na Educação II, uma perda de caminho - a liberdade de fazer de outro modo nos parece a perda de um horizonte, de algo que sabemos (16 de setembro de 2010).

Nesse sentido, antes de qualquer coisa, seria interessante lembrar, como aponta Veiga-Neto (2006), que as verdades sobre o mundo são invenções que esqueceram que o são. Dessa maneira, a forma hegemônica de aprender e ensinar ciências é apenas uma entre outras possibilidades, mas, não obstante, é também a forma hegemonizada tendo em vista um jogo de poder em cujo bojo está centrado nosso modelo social.

Por isso, a transposição desse modelo ainda tão presente, calcado na transmissão de conhecimentos e informações, requer, também, a garantia de processos formativos docentes que legitimem a conhecimento de si e os fazeres e saberes dos professores como potencias formativos. Tal concepção se alicerça na idéia de que

a identidade profissional docente deve ser entendida como prática social construída pela ação de influências e grupos que configuram a existência humana. A prática educativa é uma prática social; assim sendo, a constituição da identidade docente só acontece no âmago dessa prática e em relação com outros, com o grupo de pertença (SOUZA; D’ÁVILA, 2010, p. 447).

Logo, a (trans)formação docente se processa de maneira combinada, no e com o coletivo, por meio de diálogos, discussões e reflexões da/na/sobre a prática pedagógica. Essa assertiva nos coloca a necessidade sempre presente do diálogo entre universidade e escola básica, a fim de se possibilitarem (re)significações conjuntas das ações 
educativas, seja na dimensão da certificação inicial ${ }^{3}$, seja na dimensão da educação fundamental.

No que tange ao ensino de ciências, o diálogo entre prática e teoria, por meio de um movimento (auto)formativo, permite a refutação de um modelo de ensino de ciências em que as relações de ensino-aprendizagem são pautadas em receituários e regras prontas, "pacotes" padronizados de práticas e ações que se repetem e reproduzem o que está nos livros didáticos, enfim, relações pedagógicas alicerçadas na concepção de ciência morta (DELIZOICOV et all., 2002).

Igualmente, defendemos a problematização e o questionamento dessa forma ainda hegemônica de ensinar ciências por uma questão particular, qual seja: em nossa concepção, ela não garante aos historicamente segregados uma apropriação crítica e reflexiva do mundo. Não garante a apropriação de códigos e conhecimentos culturalmente validados dos quais eles também são produtores. Assim, ensinar ciências, na escola e além dela, de forma convidativa, questionadora, reflexiva, é uma forma de buscar propiciar espaços/tempos mais democráticos para se aprender e ensinar...

\section{3. (In)conclusões... Pensando horizontes de possibilidades para ensinos de ciências outros}

Frente à complexidade constitutiva do mundo onde vivemos, diante dos desafios e mazelas do mundo do qual somos produtores e pelo qual somos produzidos, pensamos que a educação tem um papel importante a cumprir. Não se trata da redenção tampouco da salvação social, porém é fato que, de alguma forma, trata-se de uma busca em relação à garantia de relações em cujo bojo esteja a reflexão e a problematização do ser e estar no mundo.

Nessa sociedade, o ensino de ciências traz consigo importantes contribuições para a viabilização de relações menos assimétricas e a assunção, por parte dos sujeitos, do seu ser e estar no mundo como uma condição histórica, social e culturalmente situada; primeiro, porque pode propiciar uma leitura mais ampla do mundo, sem dogmatismos que cerceiam possíveis modos de ver além das naturalizações das formas de ser/ estar culturalmente instituídas. Segundo, porque viabiliza uma apropriação dos

\footnotetext{
${ }^{3}$ Alicerçados em Souza (2006), chamamos de certificação inicial o momento do processo formativo geralmente denominado de formação inicial. Entretanto, optamos por essa nomenclatura por entender a formação como um contínuo que engloba dimensões pessoais e profissionais referentes a todas as fases da vida, motivo pelo qual desacreditamos em um marco inicial para a formação.
} 
códigos e artefatos tecnológicos e científicos da sociedade na qual o sujeito está inserido.

Sendo assim, não podemos (in)concluir nosso diálogo senão por meio da defesa do ensino de ciências como uma possibilidade de "descoberta" de mundos; descobertas fomentadas e incentivadas por perguntas dos próprios aprendentes, por acontecimentos constitutivos de seu ser-estar no mundo, do seu cotidiano. Praticar, na e com os alunos e alunas, um ensino de ciências outra prescinde de uma (re)significação da prática docente e da consecutiva indagação das maneiras insituídas de ensinar e aprender, no sentido de legitimarem-se práticas instituintes, pautadas na escuta sensível do que os estudantes tem a nos dizer, ou, mais que isso, do visto/sentido/ouvido na escola.

Cada vez mais, insistimos em um ensino de ciências que invista na narrativa, um ensino como forma de contar sobre si e sobre o mundo - ciências como histórias do mundo: a partir de suas crenças, saberes e experiências, alunos e alunas podem ampliar ainda não saberes e, cada vez mais, transpor certezas arraigadas na e pela a imersão no senso comum, problematizando e ressignificando conhecimentos.

\section{Referências}

AINKENHEAD, G. Educación Ciencia -Tecnología-Sociedad (CTS): una buena idea como quiera que se le llame. Educación Química, V.16, n. 2, abr. 2005.

AULER, D.; DELIZOICOV, D. Alfabetização científico-tecnológica para quê? Ensaio, Belo Horizonte - MG, v. 3, n. 2, dez. 2001. Disponível em: http://www.fae.ufmg.br/ensaio/v3_n2/deciodemetrio.PDF. Acesso em 20.

BACHELARD, G.(1938). A formação do espírito científico - contribuição para uma psicanálise do conhecimento. RJ:Contraponto, 2003, 316p.

BRASIL. Secretaria de Educação Fundamental. Parâmetros curriculares nacionais: ciências naturais. Brasília: MEC/ SEF, 1997. Disponível em < http://www.if.usp.br/profis/pcnef/pcn1a4/pcn_1a4_ciencias_naturais.pdf> Acesso em 15.06 .2010

COLINVAUX, D. Crianças na escola: histórias de adulto. In: MELLO, M. B. “O jeito que nós crianças pensamos sobre certas coisas" - dialogando com lógicas infantis. Rio de Janeiro: Rovelle, 2009.

DELIZOICOV, D.; ANGOTTI, J. A. P.; PERNAMBUCO, M. M. Ensino de Ciências: fundamentos e métodos. São Paulo: Cortez, 2002 
FOERSTER, H. V. Visão e conhecimento: disfunções de segunda ordem. In: SCHNITMAN, D. F. (org). Novos Paradigmas, Cultura e Subjetividade. Porto Alegre: Artes Médicas, 1996.

FREIRE, P. Pedagogia da autonomia - saberes necessários à prática educativa. 36 ed. São Paulo: Paz e Terra, 1996.

Pedagogia do Oprimido. $11^{\text {a }}$ ed. São Paulo: Paz e Terra, 1982.

FUMAGALLI, L. EI desafio de enseñar ciencias naturales. Una propuesta didáctica para la escuela media. Buenos Aires: Troquel, 1993.

MALAFAIA, G.; RODRIGUES, A. S. L. Uma reflexão sobre o ensino de ciências no nível fundamental da educação. Ciência \& Ensino. Vol. 2, n. 2, junho de 2008. Disponível

http://www.ige.unicamp.br/ojs/index.php/cienciaeensino/article/viewDownloadInterstiti

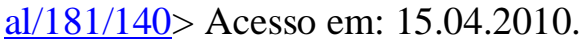

MATURANA, H. Emoções e linguagem na educação e na política. Belo Horizonte: Ed. UFMG, 1998.

MONTEIRO,R. Entre monoculturas e ecologias: a percepção do público dos museus de ciência e ténica sobre as relações Ciência, Tecnologia, Sociedade e Ambiente (CTSA). Dissertação de Mestrado em Educação, PPGEdu,UNIRIO, 2011.

SOUZA, E. C. O conhecimento de si - estágio e narrativas de formação de professores. Rio de Janeiro: DP\&A; Salvador: UNEB, 2006.

; D’ÁVILA, C. Abordagem biográfica e pesquisa educacional: convergências teórico-metodológicas e práticas de formação. In: DALBIEN, A. I. L. F. (org.). Convergências e tensões no campo da formação e do trabalho docente. Belo Horizonte: Autêntica, 2010.

VEIGA-NETO, A. Memória, tempos, cotidiano. In: GARCIA, R. L.; ZACCUR, E. Cotidiano e diferentes saberes. Rio de Janeiro: DP\&A, 2006. 